Rev. Interd. em Cult. e Soc. (RICS), São Luís, v. 7, n. 1, p. 188 - 207, jan./jun. 2021

ISSN eletrônico: 2447-6498

\title{
A importância da acessibilidade nos espaços de restauração ${ }^{1}$
}

\section{The importance of accessibility in restaurant spaces}

\author{
LUÍS VICENTE \\ Mestre \\ CRID $^{\circledR} /$ ESECS/Politécnico de Leiria, Portugal \\ luis.s.vicente@ipleiria.pt
}

CÉLIA SOUSA

Doutorada

CRID $^{\circledR} /$ ESECS/CICS.NOVA.IPLeiria/Politécnico de Leiria, Portugal celia.sousa@ipleiria.pt

ANTÓNIA BARRETO

Doutorada

ESECS/Politécnico de Leiria, Portugal

antonia@ipleiria.pt

\section{RESUMO}

Em Portugal não existe uma legislação específica a ser aplicada em espaços de restauração para os tornar acessíveis a todas as pessoas. O Decreto-Lei n. ${ }^{\circ}$ 163/2006 de 8 de agosto aprova o regime da acessibilidade de edifícios e estabelecimentos que recebem público, mas existem várias lacunas relativamente a um espaço tão específico como um restaurante, como as distâncias que devem existir entre mesas para que os funcionários e clientes com e sem mobilidade condicionada possam circular livremente. $O$ presente estudo centra-se na avaliação das acessibilidades de um restaurante. $O$ estudo é de natureza qualitativa e avalia se o restaurante apresenta acessibilidades arquitetónicas, comunicacionais, atitudinais, instrumentais e digitais que permitam a frequência de pessoas com necessidades específicas. Os resultados confirmam a possibilidade de ter um espaço físico que permite receber todas as pessoas com a comodidade e a segurança necessárias para realizar uma refeição com dignidade.

Palavras-chave: Acessibilidade. Cidadania. Comunicação. Inclusão. Restauração.

\section{ABSTRACT}

In Portugal, there is no specific legislation to apply in catering spaces to make them accessible to all people. Decree-Law 163/2006 of August 8 approves the accessibility regime of buildings and establishments that receive the public, however, there are several gaps regarding such a specific space as a restaurant, such as the distances that must exist between tables so that employees and clients with and without conditioned mobility can move freely. This study focuses on the evaluation of the accessibilities of a restaurant. The study is of qualitative nature and evaluates if the restaurant has architectural, communicational, attitudinal, instrumental and digital accessibilities that allow its attendance by people with specific needs. The re-

\footnotetext{
${ }^{1}$ Artigo submetido em 19/05/2021 e aprovado em 16/06/2021.
} 
Rev. Interd. em Cult. e Soc. (RICS), São Luís, v. 7, n. 1, p. 188 - 207, jan./jun. 2021

ISSN eletrônico: 2447-6498

sults confirm the possibility of having a physical space that allows receiving all the people with comfort and the necessary security to make a meal with dignity.

Keywords: Accessibility. Citizenship. Communication. Inclusion. Restoration.

\section{Introdução}

Este artigo baseia-se no Relatório de Projeto de Mestrado em Educação Especial no Domínio Cognitivo-Motor, intitulado "Inclusão Social: Avaliação da Acessibilidade em Equipamentos Sociais. Um Estudo de Caso" e é uma versão alargada do resumo publicado no Livro de Resumos da INCLUDiT VI (VICENTE; SOUSA; BARRETO, 2020).

A acessibilidade é essencial para todas as pessoas. Quanto mais acessível for o equipamento, o produto, o espaço ou o serviço, a probabilidade de ser utilizado por todos é efetivamente muito maior. As acessibilidades não são apenas dirigidas a pessoas com deficiência seja ela motora, visual, auditiva ou cognitiva, mas são também orientadas para crianças, pais com bebês, mulheres grávidas ou ainda para os idosos que, com o passar dos anos, vão perdendo alguma acuidade nos vários sentidos ou perdem capacidades de locomoção.

Em Portugal, o Decreto-Lei n. ${ }^{\circ}$ 123/97, de 22 de maio introduziu normas para a supressão de barreiras arquitetónicas e, posteriormente, com o Decreto-Lei n. ${ }^{\circ}$ 163/2006, de 8 de agosto surgiram normas técnicas que se aplicam às acessibilidades físicas e às acessibilidades sensoriais, abrangendo pessoas com mobilidade condicionada, pessoas com dificuldades sensoriais, tais como pessoas cegas ou surdas, e pessoas com dificuldades de caráter temporário ou transitório, como as grávidas, as crianças ou mesmo os idosos.

Para que se possa garantir a presença de pessoas com necessidades específicas num espaço de restauração é necessário criar condições físicas, atitudinais, instrumentais, comunicacionais e digitais para que estas se sintam seguras, confortáveis e principalmente incluídas.

Nesta conjuntura, formulou-se a seguinte questão de investigação: “As acessibilidades existentes no Restaurante X possibilitam a frequência de pessoas com necessidades específicas?". Para responder à questão foram delineados quatro objetivos que visam investigar as acessibilidades arquitetónicas de acordo com a legislação em vigor e o atendimento efetuado pelos funcionários do restaurante na receção ao cliente e durante a refeição, bem como a comunicação e ainda avaliar as acessibilidades digitais do website e das redes sociais utilizadas (Facebook e Instagram) e as práticas de gestão na perspetiva perspectiva da inclusão e equidade. 
Rev. Interd. em Cult. e Soc. (RICS), São Luís, v. 7, n. 1, p. 188 - 207, jan./jun. 2021

ISSN eletrônico: 2447-6498

O termo "Desenho Universal" tem origem na área arquitetónica e no presente estudo faz muito sentido este conceito, uma vez que se pretende que o restaurante seja acessível a todas as pessoas, independente da condição física, sensorial e intelectual delas. Assim, apresenta-se este conceito como um ponto central deste estudo, pelas razões já invocadas.

Este artigo tem o seu resumo publicado no livro de resumos da INCLUDiT VI (FREIRE; MANGAS; SOUSA, 2020, pp. 428-435).

\title{
A Pessoa com Deficiência no Quadro Europeu
}

Os países que pertencem à União Europeia (UE) possuem legislação própria sobre acessibilidade, com imposições bem esclarecidas, quer no acesso aos espaços físicos e arquitetónicos, na comunicação e na informação, no acesso ao emprego, nos transportes e na educação. Em 2015 foi elaborada uma Proposta de Diretiva do Parlamento Europeu e do Conselho relativa à aproximação das disposições legislativas, regulamentares e administrativas dos Estados-Membros da EU, no que diz respeito aos requisitos de acessibilidade dos produtos e serviços mencionando que:

\begin{abstract}
A acessibilidade passa pela prevenção ou a eliminação de obstáculos à utilização dos produtos e serviços mais comuns. Permite às pessoas com limitações funcionais, inclusive as pessoas com deficiência, percecionar, utilizar e compreender estes produtos e serviços, em igualdade de condições com as demais pessoas. (COMISSÃO EUROPEIA, 2015, p. 2).
\end{abstract}

De acordo com os Censos de 2011, aproximadamente 1 milhão e 800 mil pessoas (18\% da população nacional) declarou ter muitas dificuldades ou não conseguir realizar pelo menos uma de seis atividades diárias: andar ou subir degraus (25\%), ver (23\%), memorizar ou concentrar-se $(17 \%)$, ouvir (13\%), tomar banho/vestir-se sozinho (12\%) ou compreender os outros ou fazer-se compreender $(10 \%)$.

O Decreto-Lei n. ${ }^{\circ}$ 123/97, de 22 de maio “...introduziu normas técnicas, visando a eliminação de barreiras urbanísticas e arquitectónicas nos edifícios públicos, equipamentos colectivos e via pública" (Diário da República n. ${ }^{\circ}$ 118/1997), no entanto, passados nove anos da entrada em vigor deste decreto, foi aprovado o Decreto-Lei n. ${ }^{\circ} 163 / 2006$, de 8 de agosto “...visando a construção de um sistema global, coerente e ordenado em matéria de acessibilidades, susceptível de proporcionar às pessoas com mobilidade condicionada condições iguais às das restantes pessoas" (Diário da República, n. ${ }^{\circ} 152$ série I. 2006). Este último Decreto-Lei 
Rev. Interd. em Cult. e Soc. (RICS), São Luís, v. 7, n. 1, p. 188 - 207, jan./jun. 2021

ISSN eletrônico: 2447-6498

estabelece um conjunto de princípios técnicos que se encaixam no presente estudo e são aplicáveis nas acessibilidades físicas e sensoriais para um estabelecimento de restauração, cuja superfície de acesso ao público ultrapasse os $150 \mathrm{~m}^{2}$. O documento regulamenta espaços físicos de mobilidade, tais como, escadas, rampas, corredores, elevadores, a existência de pelo menos um balcão de atendimento com altura adaptada a pessoas que se deslocam em cadeira de rodas, a reserva de lugares de estacionamento para pessoas com mobilidade reduzida, ou ainda a existência de, pelo menos, uma instalação sanitária com condições para pessoas com mobilidade reduzida. O Decreto-Lei 95/2019 de 18 de julho é a última versão do Decreto-Lei n..$^{\circ}$ 163/2006, sendo que contém as atualizações constantes dos Decretos-Lei 136/2014 de 9 de setembro e 125/2017 de 4 de outubro.

\section{Acessibilidades e Desenho Universal}

A respeito disto, Gouveia (2010, p. 9), ao referir que "a Acessibilidade pode ser definida como a capacidade do meio (espaços, edifícios ou serviços) de proporcionar a todos uma igual oportunidade de uso, de uma forma directa, imediata, permanente e o mais autónoma possível”, comprova que deve existir uma igualdade de oportunidades para todos no acesso e utilização dos espaços, bens e serviços, essencial para a realização de uma vida independente e para uma participação ativa na comunidade.

No presente estudo está presente a terminologia "desenho universal", que foi criada pelo arquiteto Ronald L. Mace para descrever o modo de conceber produtos e espaços que sejam estéticos, mas sobretudo utilizáveis por todos, independentemente das suas capacidades ou da sua idade. "Universal design is the design of products and environments to be usable by all people, to the greatest extent possible, without the need for adaptation or specialized design." - Ron Mace.

Quando se projeta uma determinada acessibilidade em desenho universal, obedece-se a vários princípios (COHEN; DUARTE; BRASILEIRO, 2012; MINEIRO, 2017):

1. Uso equitativo: o design é útil e pode ser utilizado por pessoas com diferentes capacidades;

2. Flexibilidade de utilização: o design permite escolher o modo de utilização e garante adaptabilidade ao utilizador;

3. Uso simples e intuitivo: fácil de compreender, com informação coerente e acessível, independentemente das capacidades cognitivas ou linguísticas do utilizador; 
Rev. Interd. em Cult. e Soc. (RICS), São Luís, v. 7, n. 1, p. 188 - 207, jan./jun. 2021

ISSN eletrônico: 2447-6498

4. Informação percetível: com uma comunicação simples e eficaz, utilizando diferentes formatos (braille, pictogramas etc.);

5. Tolerância ao erro: minimiza riscos, alerta para os riscos ou erros, eliminando possíveis ações acidentais;

6. Esforço físico mínimo: pode ser utilizado confortavelmente e com o mínimo de fadiga;

7. Dimensão e espaço de abordagem e de utilização: o tamanho e o espaço devem ser apropriados para uma aproximação e manuseamento ao utilizador. Deve estar visível e acessível em altura a todos os que necessitam.

O conceito de "desenho para todos" é deveras difícil de atingir dada a multiplicidade humana, no entanto ao gerar condições, pensando no design universal, desenvolvem-se produtos e conceitos que podem ser experimentados por um maior número de usuários e com particularidades muito diversas, difundindo assim a inclusão social.

\section{TURISMO ACESSÍVEL}

O Restaurante $\mathrm{X}$ encontra-se num ponto estratégico, junto a três concelhos da zona centro (Leiria, Batalha e Porto de Mós) com uma elevada procura turística e ainda bem próximo do turismo religioso de Fátima, que atrai milhares de pessoas todos os anos. Estes três concelhos mencionados têm feito múltiplos esforços para que os seus espaços culturais e de lazer, abertos às suas populações, sejam cada vez mais inclusivos e o Restaurante X considerou essas preocupações e procurou fazer com que "...todas as pessoas se sintam em casa".

O Turismo de Portugal, I. P. (2012) afirma que o turismo deve estar ao alcance de todos os cidadãos e que jamais poderá ser um fator de exclusão numa sociedade que se quer inclusiva. Segundo o Código Mundial de Ética do Turismo (OMT, 1999), no seu artigo 7. , declara que:

O direito ao turismo para todos deve ser visto como corolário do direito ao repouso e aos tempos livres, e nomeadamente do direito a uma razoável limitação da duração do trabalho e licenças periódicas pagas, garantido no artigo 24 da Declaração Universal dos Direitos do Homem, e no artigo 7.1 do Pacto Internacional relativo aos direitos económicos, sociais e culturais. 
Rev. Interd. em Cult. e Soc. (RICS), São Luís, v. 7, n. 1, p. 188 - 207, jan./jun. 2021 ISSN eletrônico: 2447-6498

Darcy (2006, p.35) cita que o turismo acessível "é um processo que permite que as pessoas com deficiência e os idosos ajam independentemente, em igualdade de condições e com dignidade através da prestação de produtos, serviços e ambientes universais no turismo".

\section{Acessibilidades como Meio de Implementação dos Direitos Humanos}

O comportamento do ser humano para com o próximo nem sempre é o mais adequado, por vezes existem atitudes preconceituosas e de desrespeito. Estas atitudes podem influenciar uma pessoa ou até mesmo uma sociedade.

Como descrito por Sassaki (2009), a acessibilidade atitudinal refere-se a preconceitos e discriminações nas pessoas, sendo que as barreiras atitudinais que daí resultam são provocadas pelo comportamento dos indivíduos de forma intencional. Na opinião de Salasar (2019), as pessoas com deficiência destacam esta acessibilidade "como a principal ação de inclusão" e consiste na anulação de qualquer comportamento preconceituoso ou estigmas sobre as pessoas com deficiência. A autora está em concordância com Sassaki quando declara que estas atitudes são provocadas de "forma implícita", no entanto relata também que em determinadas situações, estas atitudes podem ser inconscientes e sem o indivíduo "dar-se conta do que acabou de fazer".

O ser humano nem sempre tem a capacidade de se colocar no papel do outro, mas quando isso acontece, percebe que não pode fazer algo ao outro se também não gosta que lhe façam a ele. Somos todos diferentes quer na forma de estar, quer na forma física, quer na forma de pensar, cada um com as suas caraterísticas, no entanto os direitos são iguais para todos.

“O princípio básico da inclusão é a EMPATIA" (SALASAR, 2019).

\section{ACESSIBILIDADES ARQUITETÓNICAS}

As acessibilidades arquitetónicas estão cada vez mais presentes nos edifícios em Portugal, sendo o Decreto-Lei 163/2006 de 8 de agosto o documento legislativo que aprova o regime das acessibilidades aos edifícios que recebem público, a via pública e ainda os edifícios habitacionais.

As barreiras existentes nos edifícios e espaços, sejam elas rampas com elevado declive, inexistência de percursos acessíveis, escadas, portas estreitas, entre outras são obstáculos ao usufruto dos utilizadores com necessidades específicas, tal como menciona Sassaki (2009). 
Rev. Interd. em Cult. e Soc. (RICS), São Luís, v. 7, n. 1, p. 188 - 207, jan.jun. 2021

ISSN eletrônico: 2447-6498

Para Salasar (2019), é muito importante acrescentar soluções para que pessoas em cadeiras de rodas tenham acesso aos objetos necessários para a sua autonomia, rebaixando o mobiliário sempre que necessário. Deve também existir um piso tátil, pois “dá a garantia para que pessoas com deficiência visual possam ter autonomia no ambiente". Salienta ainda a importância de um percurso acessível, de modo que as pessoas com deficiência possam chegar ao local pretendido com o mínimo de barreiras possíveis.

\section{Acessibilidades Comunicacionais}

A comunicação tem por base a transmissão de mensagens entre sujeitos de uma forma entendível, sendo este um processo primário de socialização. No processo comunicativo partilham-se mensagens, sentimentos e emoções que podem influenciar as atitudes do ser humano, que por sua vez, poderão reagir consoante os seus valores, crenças e a própria cultura (Sousa, 2012).

Para que a comunicação seja acessível, é fundamental que as barreiras comunicacionais sejam minimizadas, seja ela uma comunicação interpessoal, escrita ou mesmo digital. São diversas as formas de comunicar, tais como: a fala, a escrita, a utilização de imagens/pictogramas, o braille, o toque, o contacto visual, a língua gestual, entre outras e todas elas têm a mesma finalidade: interagir com o outro, transmitir ideias, sensações, emoções, “sem barreiras na comunicação entre pessoas” (SASSAKI, 2009).

\section{Acessibilidades Instrumentais}

Todos os instrumentos, ferramentas ou utensílios utilizados para executar determinadas tarefas geralmente são padronizados, o que impede que pessoas com algumas necessidades específicas, nomeadamente ao nível motor ou mesmo sensorial, consigam utilizá-los com eficácia. Assim, tornou-se fundamental eliminar barreiras e tornar esses mesmos instrumentos, utensílios ou ferramentas mais acessíveis, dando-lhes um novo design ou aplicando soluções diversas que lhes permitam ser utilizadas por todos.

São vários os autores que defendem a eliminação de barreiras nos instrumentos, utensílios ou ferramentas, tais como Melo (2006), Sassaki (2009), Cohen, Duarte \& Brasileiro (2012), Salasar (2019), alegando que estes instrumentos e utensílios são possíveis de serem utilizados por qualquer indivíduo, dependendo da sua utilidade final. 
Rev. Interd. em Cult. e Soc. (RICS), São Luís, v. 7, n. 1, p. 188 - 207, jan.jun. 2021

ISSN eletrônico: 2447-6498

\section{Acessibilidades Digitais}

O termo "acessibilidade web" refere-se à prática de execução inclusiva de websites, de forma a poderem ser utilizados por todos, independentemente das suas capacidades. Quando um website é concebido e editado a pensar na utilização por todas as pessoas, todos os utilizadores têm acesso à informação.

O World Wide Web Consortium (W3C) é a organização responsável pela padronização da World Wibe Web, constituída por cerca de 450 membros, desde empresas, órgãos governamentais ou organizações independentes cujo principal objetivo é estabelecer padrões de desenvolvimento, criação e interpretação de conteúdos para a web.

Em Portugal, o Decreto-Lei n. ${ }^{\circ}$ 83/2018 de 19 de outubro vem ao encontro da Diretiva 2016/2102 da UE, alargando assim o âmbito da Lei n. ${ }^{\circ}$ 36/2011 de 21 de junho "que estabelece a adoção de normas abertas nos sistemas informáticos do Estado, à Administração Pública local e a funções consideradas essenciais, no que diz respeito à acessibilidade do conteúdo de sítios web e de aplicações móveis". Este Decreto-Lei estabelece normas de acessibilidade web e aplicações móveis de organismos públicos, colmatando assim uma lacuna no serviço público e permite que todas as pessoas tenham acesso de uma forma equitativa ao serviço digital do Estado Português.

\section{ESTUDO EMPÍRICO}

A questão de investigação, segundo Quivy (1992) “[...] deve ser clara, exequível e pertinente" (cf. DIAS, 2009, p. 119) e o investigador, com a finalidade de compreender as acessibilidades já existentes e identificar as lacunas no Restaurante X, estabeleceu a seguinte pergunta de partida:

As acessibilidades existentes no Restaurante $\mathrm{X}$ possibilitam a frequência de pessoas com necessidades específicas?

De acordo com a questão de investigação, consideramos os seguintes objetivos:

- Analisar as acessibilidades físicas do restaurante de acordo com a legislação enquadradora;

- Analisar o atendimento efetuado pelos funcionários do restaurante, relativamente ao acompanhamento a indivíduos com necessidades específicas e à forma de comunicar com estes; 
Rev. Interd. em Cult. e Soc. (RICS), São Luís, v. 7, n. 1, p. 188 - 207, jan./jun. 2021

ISSN eletrônico: 2447-6498

- Avaliar se o website e as redes sociais estão acessíveis a pessoas com deficiência visual e auditiva;

- Avaliar as práticas de gestão na perspetiva da inclusão e equidade.

O presente estudo foi desenvolvido com base numa metodologia de caráter qualitativo utilizando como técnica de investigação o estudo de caso, sendo o Restaurante X o caso de estudo e as amostras são quatro pessoas com deficiência e a gestora do restaurante.

Para a recolha de dados, o investigador aplicou uma checklist, desenvolvida por Negreiros (2017), e adaptada, tendo por base o Decreto-Lei 163/2006 de 8 de agosto que aprova o regime da acessibilidade aos edifícios e estabelecimentos que recebem público, via pública e edifícios habitacionais, composta por seis blocos: gestão, acessibilidade arquitetónica, acessibilidade comunicacional, acessibilidade atitudinal, acessibilidade programática e acessibilidade instrumental. Existe um sétimo bloco intitulado "Circulação e Lay-Out", uma adaptação de um estudo de Panero \& Zelnik (2001), que consiste no estudo das acessibilidades dos espaços para tomar as refeições e do espaço em volta das mesas e cadeiras.

Quatro pessoas com deficiência (uma pessoa com deficiência visual, uma pessoa com deficiência intelectual, uma pessoa com deficiência motora e uma pessoa com deficiência auditiva) foram convidadas a jantar no Restaurante $\mathrm{X}$ e deste modo o investigador pôde utilizar a observação direta como forma de analisar o comportamento dos funcionários que receberam os convidados, o modo como os dirigiram à mesa estipulada, a comunicação utilizada entre o funcionário e o cliente, o atendimento antes, durante e após a refeição, ou seja, todas as acessibilidades atitudinais.

No final do jantar foi aplicado um Focus Group, moderado pelo investigador. Após esta primeira discussão com as pessoas com deficiência, a gestora da restauração foi convidada a juntar-se ao debate. No Focus Group as pessoas com deficiência abordaram as acessibilidades atitudinais, arquitetónicas, comunicacionais, instrumentais e da comunicação digital através do site oficial e das páginas de Facebook e Instagram.

Os resultados do presente estudo foram apresentados após análise da checklist, do Focus Group e da observação direta decorrente do jantar que juntou quatro pessoas com deficiência. 
Rev. Interd. em Cult. e Soc. (RICS), São Luís, v. 7, n. 1, p. 188 - 207, jan./jun. 2021

ISSN eletrônico: 2447-6498

\section{APRESENTAÇÃO E DISCUSSÃO DOS RESULTADOS}

Para responder ao objetivo "Analisar as acessibilidades arquitetónicas do restaurante de acordo com a legislação enquadradora" foi analisado o Decreto-Lei 163/2006 de 8 de agosto e transposto para a checklist que serve de instrumento de recolha de dados para todas as acessibilidades arquitetónicas do edifício e dos espaços que estão à volta.

Os dados obtidos com a aplicação da checklist, das observações e do Focus Group foram analisados em conjunto.

Tabela 1: Itens de avaliação das rampas que não obedecem ao Decreto-Lei 163/2006 de 8 de agosto

\begin{tabular}{|c|c|}
\hline ACESSIBILIDADE ARQUITETÓNICA & $\begin{array}{c}\text { NÃO OBE- } \\
\text { DECE }\end{array}$ \\
\hline Capítulo 5 - Rampas & $\mathbf{X}$ \\
\hline $\begin{array}{c}\text { m) O revestimento de piso das rampas, no seu início e fim, deve } \\
\text { ter faixas com diferenciação de textura e cor contrastante re- } \\
\text { lativamente ao pavimento adjacente. }\end{array}$ & \\
\hline
\end{tabular}

Gráfico 1 - Resultado da análise das acessibilidades das rampas

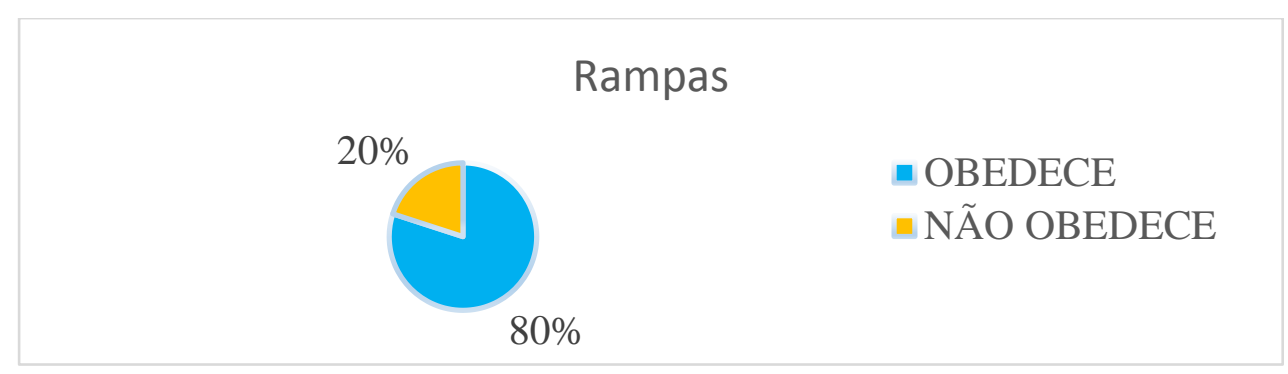

A única rampa existente, no seu ponto mais alto, tem $5 \mathrm{~cm}$ de altura, sendo que tem ainda 5,17 m de comprimento e 1,72 m de largura. Para o cálculo da percentagem de inclinação o investigador utilizou a seguinte fórmula:

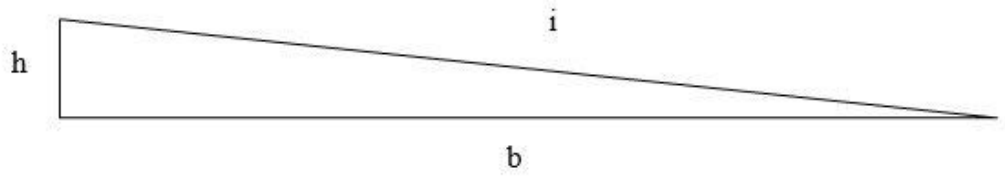

$$
\begin{aligned}
& \mathrm{i}=\text { inclinação } \\
& \mathrm{h}=\text { altura } \\
& \mathrm{b}=\text { base }
\end{aligned}
$$


Rev. Interd. em Cult. e Soc. (RICS), São Luís, v. 7, n. 1, p. 188 - 207, jan./jun. 2021

ISSN eletrônico: 2447-6498

Assim, $500 \div 517=0,967 \%$

Concluímos que, relativamente à alínea a) a inclinação é muito inferior aos $6 \%$, máximo permitido por lei e que a projeção horizontal $(5,17 \mathrm{~m})$ é também inferior aos $10 \mathrm{~m}$ permitidos. De acordo com a alínea d), a largura está de acordo com a lei, pois tem $52 \mathrm{~cm}$ a mais relativamente ao mínimo exigido por lei. A rampa existente está também dispensada de possuir corrimão, uma vez que cumpre com todos os requisitos estipulados na alínea h) da checklist.

Quanto à alínea m), o investigador identificou a ausência das "faixas com diferenciação de textura e cor contrastantes relativamente ao piso adjacente, sendo este o único ponto negativo neste capítulo.

Tabela 2: Itens de avaliação dos espaços para estacionamento de viaturas que não obedecem ao Decreto-Lei 163/2006 de 8 de agosto

\begin{tabular}{|c|c|}
\hline ACESSIBILIDADE ARQUITETÓNICA & $\begin{array}{c}\text { NÃO OBE- } \\
\text { DECE }\end{array}$ \\
\hline Capítulo 8 - Espaços para estacionamento de viaturas & \\
\hline k) Os lugares de estacionamento reservados devem ser reserva- \\
$\begin{array}{l}\text { dos por um sinal horizontal com o símbolo internacional de } \\
\text { acessibilidade, pintado no piso em cor contrastante com a da } \\
\text { restante superfície e com uma dimensão não inferior a 1 m de } \\
\text { lado, e por um sinal vertical com o símbolo de acessibilidade, } \\
\text { visível mesmo quando o veículo se encontra estacionado. }\end{array}$ \\
\hline
\end{tabular}

Gráfico 2 - Resultado da análise dos espaços para estacionamento de viaturas 
Rev. Interd. em Cult. e Soc. (RICS), São Luís, v. 7, n. 1, p. 188 - 207, jan./jun. 2021 ISSN eletrônico: 2447-6498

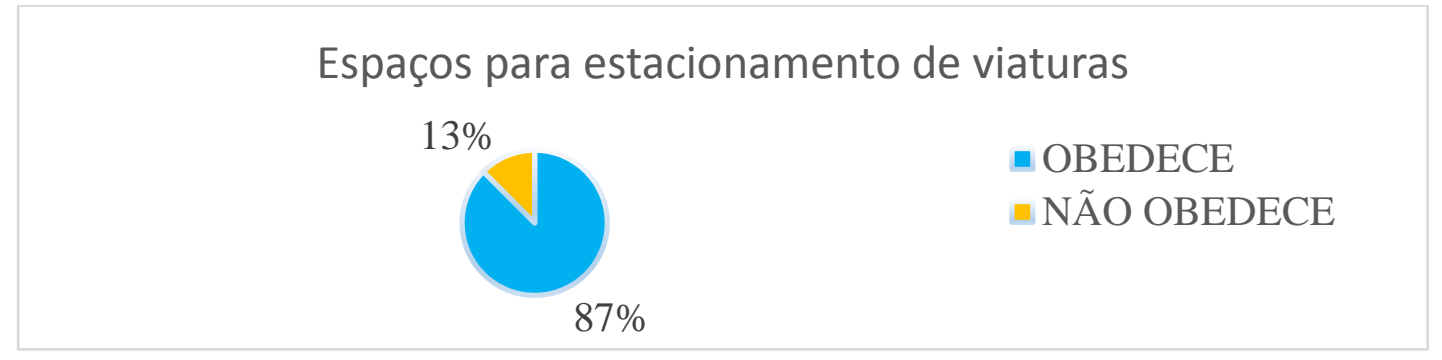

Existem no total 142 lugares para estacionamento de viaturas ligeiras. Destes, 4 lugares são para pessoas com mobilidade reduzida e 4 lugares de estacionamento para autocarros. Os lugares para pessoas com mobilidade reduzida são aqueles que mais próximo se encontram da entrada/saída do restaurante, o que corresponde ao solicitado na alínea i), estão devidamente demarcados por linhas pintadas em conformidade com a alínea k) e os mais próximos da rampa. Neste sentido, a alínea d), que contempla pelo menos 4 lugares de estacionamento para pessoas com mobilidade condicionada para uma lotação compreendida entre 101 e 500 lugares de estacionamento, está a ser cumprida de acordo com o Decreto. Apontamos a alínea 1) como "Não Obedece" apesar de podermos observar o símbolo internacional de acessibilidade pintado no piso de acordo com a legislação, no entanto o "sinal vertical com o símbolo de acessibilidade" não se encontra visível quando o veículo se encontra estacionado.

Tabela 3: Itens de avaliação das instalações sanitárias de utilização geral que não obedecem ao Decreto-Lei 163/2006 de 8 de agosto

\begin{tabular}{|c|c|}
\hline ACESSIBILIDADE ARQUITETÓNICA & $\begin{array}{c}\text { NÃO OBE- } \\
\text { DECE }\end{array}$ \\
\hline Capítulo 9 - Instalações sanitárias de utilização geral & $\mathbf{X}$ \\
\hline z) O bordo superior da superfície refletora do espelho deve estar \\
a uma altura do piso não inferior a 1,8 m. & $\mathbf{X}$ \\
\hline bb) Os terminais do sistema de aviso devem estar colocados a \\
$\begin{array}{l}\text { uma altura do piso compreendida entre 0,4 m e 0,6 m, e de } \\
\text { modo que possam ser alcançados por uma pessoa na posição } \\
\text { deitada no chão após uma queda ou por uma pessoa em ca- } \\
\text { deira de rodas. }\end{array}$ \\
\hline
\end{tabular}

Gráfico 3 - Resultado da análise das instalações sanitárias de utilização geral 
Rev. Interd. em Cult. e Soc. (RICS), São Luís, v. 7, n. 1, p. 188 - 207, jan./jun. 2021 ISSN eletrônico: 2447-6498

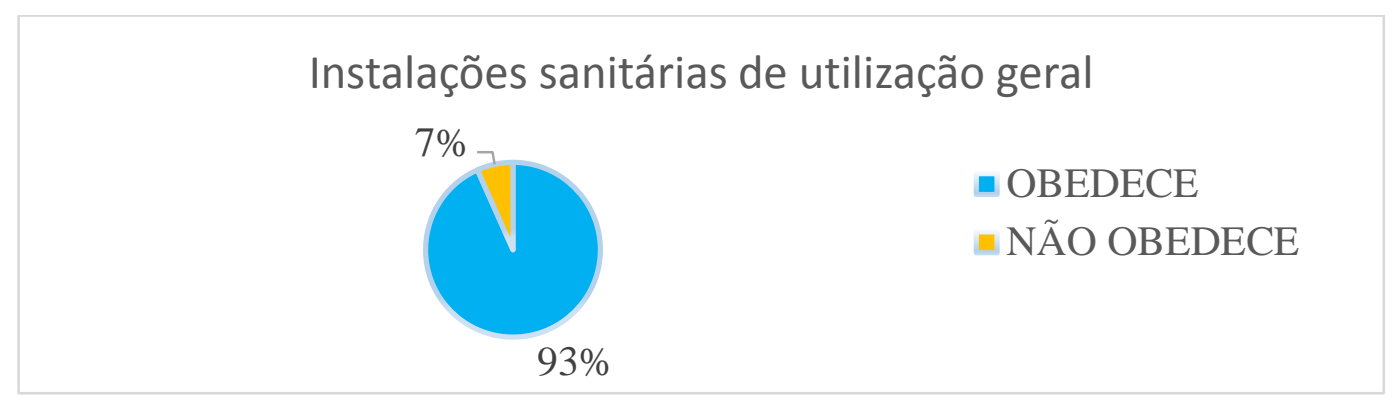

As casas de banho estão de acordo com a grande maioria das alíneas descritas na legislação (foram avaliadas trinta e uma alíneas), no entanto existem dois pontos que mereceram "nota negativa". A legislação especifica que "O bordo superior da superfície refletora do espelho deve estar a uma altura do piso não inferior a 1,8 m", no entanto o bordo superior do espelho está a 1,62 m do piso, ou seja, $18 \mathrm{~cm}$ abaixo do limite estipulado.

Relativamente à segunda alínea que consiste na altura do terminal do sistema de aviso, este encontra-se a $37 \mathrm{~cm}$ do piso, quando deveria estar entre os $40 \mathrm{~cm}$ e os $60 \mathrm{~cm}, 3 \mathrm{~cm}$ abaixo do valor mínimo.

Durante o Focus Group o investigador solicitou às duas pessoas que utilizaram a casa de banho a opinião e o parecer delas sobre as condições e acessibilidades que encontraram e se detetaram a inexistência de algo que lhes poderia ter sido útil. A pessoa com deficiência intelectual e desenvolvimental, que também se desloca em cadeira de rodas, relatou que o caixote do lixo tem abertura com pedal. Sendo uma pessoa com paraplegia, não tinha capacidade de pisar no pedal para o abrir e, sentada na cadeira não se sentia muito segura para abrilo com as mãos. Ela sugeriu a existência de um caixote de lixo com um sensor de movimento, para que, quando a mão se aproximasse do dispositivo, a tampa do caixote se abrisse e fosse possível deitar o lixo. A legislação em vigor é omissa nesta situação.

No bloco "Acessibilidade Arquitetónica" existem no total 213 itens, sendo que 124 deles não foram avaliados por se tratar de situações "Não Aplicáveis" ao espaço físico do restaurante. Foram avaliados como "Obedece", cerca de 85 itens e 4 "Não Obedecem” ao Decreto-Lei 163/2006 de 8 de agosto.

Gráfico 4 - Resultados do bloco "Acessibilidade Arquitetónica" 
Rev. Interd. em Cult. e Soc. (RICS), São Luís, v. 7, n. 1, p. 188 - 207, jan./jun. 2021 ISSN eletrônico: 2447-6498

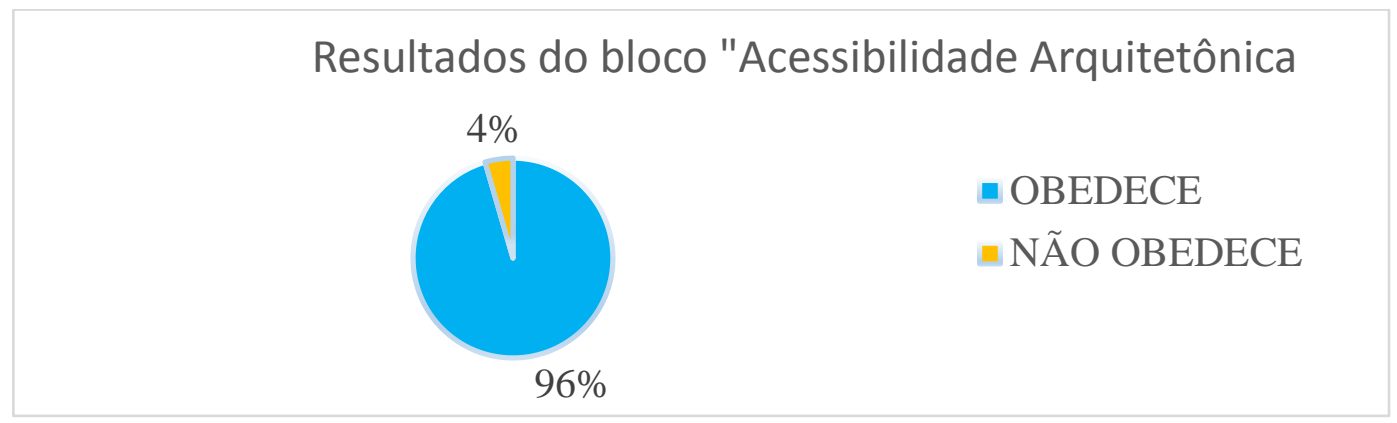

O bloco "Circulação e Lay-Out" visa analisar o espaço onde decorrem as refeições e todo o espaço em volta. As acessibilidades necessárias para se tomar uma refeição e o espaço que deve estar livre em redor das mesas estão omissos na lei, no entanto o investigador, baseado num estudo de Panero \& Zelnik (2001), analisou e identificou o espaço necessário para a mesa e ao redor dela, para se realizarem as refeições com conforto e sem perturbações. As mesas e as medidas existentes no estudo de Panero \& Zelnik (2001) foram alteradas pelo investigador, depois de analisado o espaço físico do Restaurante $\mathrm{X}$, de forma a estudar o espaço real deste restaurante. Foram feitos diversos testes e medições de forma a aprimorar o espaço quer para o cliente, quer para o funcionário que o irá servir. Na opinião da pessoa com deficiência motora que esteve presente no Focus Group, "Não há qualquer dificuldade de circular entre mesas. Há bastante espaço entre elas”.

Existem quatro tipos diferentes de mesas no restaurante: mesas para duas, quatro, seis e oito pessoas. Todas as mesas são retangulares, à exceção da mesa para oito pessoas que é circular.

Conclui-se assim que devem estar disponíveis as seguintes medidas adequadas para o espaço em volta da mesa para duas pessoas:

Figura 1: Medidas em redor de uma mesa para duas pessoas

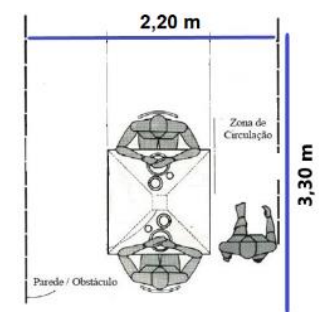

Quanto à mesa para quatro pessoas, esta mede de comprimento cerca de $160 \mathrm{~cm}$ e de largura $80 \mathrm{~cm}$. Também para este tipo de mesa estão contemplados $75 \mathrm{~cm}$ para que a circulação se faça sem constrangimentos. Nesta mesa, por estarem duas pessoas sentadas lado a lado, 
Rev. Interd. em Cult. e Soc. (RICS), São Luís, v. 7, n. 1, p. 188 - 207, jan./jun. 2021

ISSN eletrônico: 2447-6498

é importante que entre elas exista um espaço livre de pelo menos $20 \mathrm{~cm}$ de modo que elas estejam confortáveis e possam realizar a refeição sem se sentirem incomodadas pela pessoa sentada ao lado.

As medidas adequadas para o espaço em volta da mesa para quatro pessoas são as seguintes:

Figura 2: Medidas em redor de uma mesa para quatro pessoas

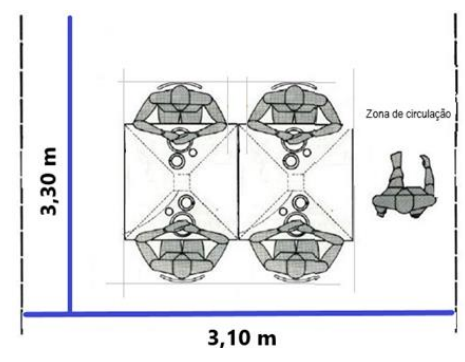

Relativamente à mesa para seis pessoas, esta tem a particularidade de ter três cadeiras e um sofá para três pessoas. A mesa mede de comprimento cerca de $180 \mathrm{~cm}$ e de largura $80 \mathrm{~cm}$. Para esta mesa estão contemplados $75 \mathrm{~cm}$ para que a circulação seja fluida.

As medidas adequadas em redor da mesa para seis pessoas.

Figura 3: Medidas em redor de uma mesa para seis pessoas são:

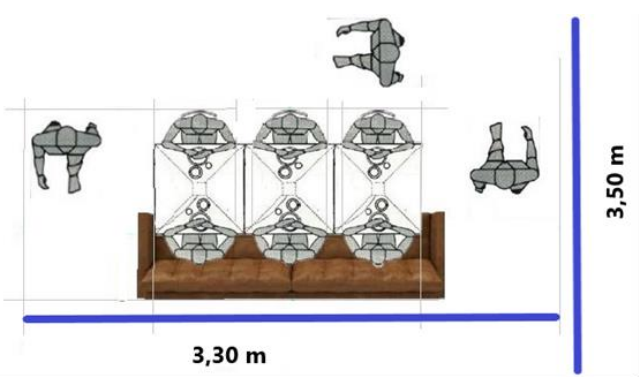

Por fim, a mesa para oito pessoas é a única que tem forma circular. O diâmetro da mesa é $183 \mathrm{~cm}$ e o diâmetro útil, incluindo a zona de circulação, é de pelos menos $430 \mathrm{~cm}$.

No jantar com as pessoas com deficiência, que ocorreu nesta investigação, foi utilizada uma mesa de oito lugares e no Focus Group foi solicitado a estas mesmas pessoas que dessem a opinião sobre as condições que encontraram à mesa. A pessoa com deficiência visual mencionou que existia "Muito espaço entre as pessoas e muito espaço para fazer a refeição". A pessoa com deficiência auditiva relatou que "a cadeira é muito confortável e tenho muito espaço" e este comentário foi reforçado pela pessoa com deficiência visual dizendo que "A cadeira é mesmo confortável... não estou nada cansada de estar sentada". Quanto à altura 
Rev. Interd. em Cult. e Soc. (RICS), São Luís, v. 7, n. 1, p. 188 - 207, jan./jun. 2021 ISSN eletrônico: 2447-6498

da mesa, a pessoa com deficiência motora disse que "já fui a muitos restaurantes e às vezes batem os joelhos" e ainda "esta mesa está muito bem". A pessoa com deficiência intelectual mencionou que "Para mim está bem", algo que foi confirmado pela pessoa com deficiência auditiva. A pessoa com deficiência visual estranhou não encontrar qualquer "perna da mesa" e foi-lhe explicado que apenas existia uma única coluna no centro da mesa com uma base. Quanto ao espaço para tomarem a refeição, todos concordaram que havia muito espaço entre as pessoas.

Relativamente às acessibilidades comunicacionais, de acordo com os estudos de Sassaki (2009), os funcionários que interagiram com as pessoas com deficiência tiveram atitudes de grande profissionalismo e humanismo. Não se observaram quaisquer tipos de "preconceitos e discriminações" em momento algum. Como afirma Salasar (2019), "O princípio básico da inclusão é a EMPATIA".

No que diz respeito à comunicação entre funcionários e clientes com deficiência, apenas foram registradas algumas dificuldades com a pessoa com deficiência auditiva e em certos momentos com a pessoa com deficiência intelectual e desenvolvimental (DID). Como menciona Sousa (2012), na comunicação "partilham-se mensagens, sentimentos e emoções" e isso foi verificado entre os vários intervenientes.

Quanto à avaliação da acessibilidade dos websites e das redes sociais a pessoas com deficiência visual, auditiva e intelectual e desenvolvimental, o investigador avaliou as páginas do Grupo Y (grupo do qual faz parte o Restaurante X) e do Restaurante X no site "Access Monitor" (https://accessmonitor.acessibilidade.gov.pt/), pertencente ao Estado Português, onde é possível estimar o grau de acessibilidade de sítios da Internet. A escala de avaliação vai de 0 valores, sendo o valor mais baixo da avaliação, até 10 valores, o valor que contempla a total acessibilidade do site avaliado.

Relativamente ao site do Grupo Y, apresenta uma pontuação de 6,4, tendo sido avaliados 526 elementos HTML, nos quais se detectaram 13 práticas a corrigir, sendo que 4 são consideradas "aceitáveis", 3 "para ver manualmente e 6" não aceitáveis". Quanto ao site do Restaurante X, o investigador constatou que a avaliação é também de 6,4 valores, uma avaliação realizada a 640 elementos HTML, observando-se 15 práticas a melhorar, das quais 4 são consideradas "aceitáveis", 3 "para ver manualmente" e 8 práticas "não aceitáveis". 
Rev. Interd. em Cult. e Soc. (RICS), São Luís, v. 7, n. 1, p. 188 - 207, jan./jun. 2021 ISSN eletrônico: 2447-6498

Quanto às redes sociais, Instagram e Facebook possuem texto simples e de fácil compreensão, no entanto faltam as descrições das imagens para as pessoas com deficiência visual.

Existe também uma grande preocupação por parte da gestora do restaurante em ouvir as pessoas e perceber o que está correto e o que não está correto para poder melhorar, quando diz "Agradecemos a todos os que vêm cá e nos deem o feedback do que está bem e menos bem, para podermos melhorar. Temos a noção de que ainda há muito a fazer."

Na gestão comunicacional do restaurante é possível verificar resultados já apresentados anteriormente, em que é notório o baixo investimento nas plataformas digitais, em relação às acessibilidades e aos conhecimentos básicos na comunicação com pessoas com deficiência auditiva.

De acordo com a gestora do restaurante, esforços têm sido feitos para oferecer formação na área da inclusão e acessibilidades aos seus funcionários, tal como ela relata: "nós já o fizemos com o projeto há três anos com a (...) da Acessible Portugal e queremos continuar a fazê-lo, para que todos os meus funcionários se sintam seguros, confiantes e preparados para receber qualquer pessoa".

A igualdade de oportunidades é também um ponto forte deste restaurante, pois além de permitir a frequência de todas as pessoas, independente das suas capacidades, também não coloca impedimentos na contratação de pessoas. A gestora declara que “...temos conosco uma pessoa com deficiência intelectual e que tem uma percentagem de invalidez.

A gestora do restaurante faz ainda referência à existência de um Regulamento Interno em que "estão contempladas orientações para o tratamento dos clientes de forma a que todos se sintam incluídos".

No que concerne aos instrumentos ou produtos de apoio disponíveis por parte da gestão do restaurante aos seus clientes, pudemos aferir que existem diversos tipos de talheres, copos, pratos e outros. Isso foi possível comprovar, uma vez que a pessoa com deficiência visual necessitou de um outro tipo de faca, com um cabo maior, e o utensílio foi substituído de imediato. A pessoa com DID necessitou também de um copo diferente e este prontamente foi-lhe entregue. Na mesa existiam também pratos diferenciados, de acordo com o solicitado por cada uma das pessoas. 
Rev. Interd. em Cult. e Soc. (RICS), São Luís, v. 7, n. 1, p. 188 - 207, jan.jun. 2021

ISSN eletrônico: 2447-6498

Para a consulta dos pratos foi disponibilizado pelo funcionário um tablet, pois as ementas em formato físico (papel), algo que foi solicitado pelo investigador com alguma antecedência, pois devido à pandemia, tal não está a ser aconselhado pelo Governo Português.

O facto de existirem tais acessibilidades no restaurante coincide com os estudos de Melo (2006), Sassaki (2009), Cohen, Duarte \& Brasileiro (2012) e Salasar (2019) quando estes referem que os instrumentos e utensílios são possíveis de serem utilizados por qualquer indivíduo, dependendo da sua utilidade final, quando não se pensa somente na padronização.

\section{CONCLUSÕES}

O presente estudo destaca a importância das acessibilidades nos espaços de restauração, não apenas as arquitetónicas, mas também as comunicacionais, instrumentais, atitudinais e digitais para que qualquer pessoa possa aceder, frequentar e realizar uma refeição de uma forma digna e confortável.

Relativamente à questão de investigação "As acessibilidades existentes no Restaurante X possibilitam a frequência de pessoas com necessidades específicas?" verificou-se que acerca das acessibilidades arquitetónicas, é possível afirmar que, de acordo com o DecretoLei 163/2006 de 8 de agosto, o restaurante cumpre com a maioria das alíneas e que o atendimento prestado pelas funcionárias na receção e pelo funcionário no atendimento à mesa foram exemplares. No que diz respeito à comunicação, observou-se alguma dificuldade com a pessoa com deficiência auditiva devido à reconhecida falta de formação dos seus funcionários nesta área da comunicação, tal como reconhece a gestora do restaurante. As acessibilidades digitais são as que mais carecem de atenção, pois a análise efetuada pelo investigador através do site "Access Monitor" revela a existência de alguns erros técnicos que devem ser corrigidos para uma melhor leitura, principalmente por pessoas com deficiência visual. Quanto às redes sociais (Instagram e Facebook), estas carecem da descrição das imagens. Na análise à gestão do restaurante, verificou-se um baixo investimento na comunicação com o exterior através dos seus websites e redes sociais, reforçando assim a avaliação mais pormenorizada às acessibilidades digitais que revelaram um pior desempenho. 
Rev. Interd. em Cult. e Soc. (RICS), São Luís, v. 7, n. 1, p. 188 - 207, jan./jun. 2021

ISSN eletrônico: 2447-6498

\section{REFERÊNCIAS}

COHEN, R.; DUARTE, C.; BRASILEIRO, A. Acessibilidade a Museus: Cadernos Museológicos - Volume 2. Brasília, Ibram, 2012.

COMISSÃO EUROPEIA (2015). Proposta de Diretiva do Parlamento Europeu e do Conselho relativa à aproximação das disposições legislativas, regulamentares e administrativas dos Estados-Membros no que respeita aos requisitos de acessibilidade dos produtos e serviços. Comissão Europeia. https://eur-lex.europa.eu/resource.html?uri=cellar:202aa1e4-99a011e5-b3b7-01aa75ed71a1.0015.02/DOC_1\&format=PDF

Decreto-Lei n. ${ }^{\circ}$ 123/1997 do Ministério da Solidariedade e Segurança Social (1997). Diário da República n. ${ }^{\circ}$ 118/1997, Série I-A. https://dre.pt/pesquisa/-

/search/397953/details/maximized

Decreto-Lei n. ${ }^{\circ}$ 163/2006 do Ministério do Trabalho e da Solidariedade Social (2006). Diário da República n. ${ }^{\circ}$ 152/2006, Série I. https://data.dre.pt/eli/dec-lei/163/2006/08/08/p/dre/pt/html

Decreto-Lei n. ${ }^{\circ}$ 136/2014 do Ministério do Ambiente, Ordenamento do Território e Energia (2014). Diário da República n. ${ }^{\circ}$ 173/2014, Série I. https://dre.pt/pesquisa//search/56501680/details/maximized

Decreto-Lei n. ${ }^{\circ}$ 125/2017 do Ministério do Trabalho, Solidariedade e Segurança Social (2017). Diário da República n. ${ }^{\circ}$ 192/2017, Série I. https://dre.pt/home//dre/108244274/details/maximized

Decreto-Lei n. ${ }^{\circ}$ 95/2019 da Presidência do Conselho de Ministros (2019). Diário da República n. ${ }^{o}$ 136/2019, Série I. https://dre.pt/home/-/dre/123279819/details/maximized

DIAS, M. O. (2009). O Vocabulário do Desenho de Investigação, A Lógica do Processo em Ciências Sociais. Psicosoma.

GOUVEIA, P. H. (Coord.). Turismo Acessível em Portugal - Lei, oportunidades económicas, informação. Portugal, Instituto Nacional para a Reabilitação, 2010. Coleção Informar. Disponível em:

<https://www.inr.pt/documents/11309/215189/turismo_acessivel_em_portugal.pdf/c652f1cbfa51-4fa5-89c0-9eb2eb6b06d8>

NEGREIROS, D. A. Potenciar a acessibilidade cultural em ambientes culturais: um estudo exploratório em Museus [Dissertação de Mestrado]. Leiria, Escola Superior de Educação e Ciências Sociais de Leiria, 2017.

https://iconline.ipleiria.pt/bitstream/10400.8/2914/1/07_Dilma_Negreiros_novembro_2017.pd $\underline{\mathrm{f}}$

PANERO, J.; ZELNIK, M. (s.d.). Las dimensiones humanas en los espacios interiores - Estándares antropométricos. São Paulo, Editora Gg, 1984. Disponível em:

<https://www.academia.edu/35335616/Panero_y_Zelnik__LAS_DIMENSIONES_HUMANAS_EN_ESPACIOS_INTERIORES.pdf> 
Rev. Interd. em Cult. e Soc. (RICS), São Luís, v. 7, n. 1, p. 188 - 207, jan./jun. 2021 ISSN eletrônico: 2447-6498

SALASAR, D.N. Um Museu para Todos: Manual de Programas de Acessibilidade. Pelotas, Universidade Federal de Pelotas, 2019. Disponível em:

<http://guaiaca.ufpel.edu.br/handle/prefix/4390>

SASSAKI, R.K. Inclusão: Acessibilidade no lazer, trabalho e educação. In: Revista Nacional de Reabilitação (Reação), São Paulo, Ano XII, mar./abr. 2009, p. 10-16. Disponível em: https://acessibilidade.ufg.br/up/211/o/SASSAKI__Acessibilidade.pdf?1473203319

SOUSA, C. O conhecimento que os professores manifestam sobre a metacognição da comunicação não-verbal na escola inclusiva: respostas aos alunos com NEE [tese de doutoramento]. Espanha, Universidad de Extremadura, 2012. Disponível em:

<http://dehesa.unex.es/handle/10662/437>

VICENTE, L.; SOUSA, C.; BARRETO, A. A importância da acessibilidade nos espaços de restauração [Sessão em conferência]. VI Conferência Internacional para a Inclusão, Leiria, Instituto Politécnico de Leiria, 2020. http://hdl.handle.net/10400.8/5376 